\title{
Automated RFLP pattern comparison and similarity coefficient calculation for rapid delineation of new and distinct phytoplasma $16 \mathrm{Sr}$ subgroup lineages
}

Correspondence

Yan Zhao

yan.zhao@ars.usda.gov

\author{
Wei Wei, Ing-Ming Lee, Robert E. Davis, Xiaobing Suo and Yan Zhao \\ Molecular Plant Pathology Laboratory, USDA-Agricultural Research Service, Beltsville, MD 20705, \\ USA
}

\begin{abstract}
Phytoplasmas are cell wall-less bacteria that cause numerous diseases in several hundred plant species. During adaptation to transkingdom parasitism in diverse plant and insect hosts, phytoplasma evolution has given rise to widely divergent lineages. Since phytoplasmas cannot be cultured in a cell-free medium, measurable phenotypic characters suitable for conventional microbial classification are mostly inaccessible. Currently, phytoplasma differentiation and classification are mainly dependent on restriction fragment length polymorphism (RFLP) analysis of 16S rRNA gene sequences. Extending our recent efforts in the exploitation of computersimulated 16S rRNA gene RFLP analysis and virtual gel plotting for rapid classification of phytoplasmas, we have developed a Perl program for automated RFLP pattern comparison and similarity coefficient calculation. This program streamlines virtual RFLP pattern analysis and has led to the establishment of a criterion for phytoplasma $16 \mathrm{Sr}$ subgroup classification and to the delineation of new and distinct subgroup lineages in the clover proliferation phytoplasma group $(16 \mathrm{SrVl})$.
\end{abstract}

Phytoplasmas are a large group of cell wall-less bacteria that cause numerous diseases in several hundred plant species including economically important vegetable, cereal, fruit, ornamental and forest crops worldwide (McCoy et al., 1989; Lee et al., 2000). Phytoplasmas reside in the sieve cells of plant phloem tissue and are transmitted by phloem-feeding insect vectors (Tsai, 1979). Together with acholeplasmas, mycoplasmas, spiroplasmas and other cell wall-less bacteria, phytoplasmas are classified in the class Mollicutes. Although phytoplasmas form a large discrete monophyletic group within the Mollicutes phylogenetic tree (Weisburg et al., 1989; Gundersen et al., 1994; Wei et al., 2007), phytoplasmas have evolved to give rise to widely divergent lineages in adaptation to transkingdom parasitism in diverse plant and insect hosts. The biodiversity of phytoplasmas has long been recognized, even at the time when the aetiological agents of phytoplasmal diseases (yellows diseases) were mistakenly assumed to be viruses. Initially, differentiation of phytoplasmas or presumed 'yellows viruses' was based on the geographical origins of the diseases, on the identity of specific plant hosts and insect vectors, and on the symptoms exhibited by the diseased plants (Chiykowski, 1962; Freitag, 1964;

The Perl program (RFLP_pattern_comparison.pl), an accessory file (restriction_enzyme_list.txt) and an example of an input file (i.e. a list of sequences; sample_input_file.fas) and a table detailing the coefficients of pattern similarity determined in this study are available with the online version of this paper.
Granados \& Chapman, 1968; Chiykowski \& Sinha, 1989; McCoy et al., 1989). In the 1980s and early 1990s, creative applications of serological (Lin \& Chen, 1985; Lee et al., 1993a) and nucleic acid-based (Lee \& Davis, 1988; Lee et al., 1992a, b) assay techniques produced new insights into the diversity and genetic interrelationships among phytoplasma strains and led to the recognition of distinct serological groups and genomic clusters. However, despite such knowledge, taxonomy and classification of diverse phytoplasmas have remained formidable challenges, largely due to the inability to culture phytoplasmas in cell-free media and the consequent inaccessibility of measurable phenotypic characters that are traditionally used for the differentiation and classification of culturable microbes.

Over the past two decades, advances in the molecular biology and phylogeny of bacteria have changed the concept of mollicute taxonomy (Razin et al., 1998; Lee et al., 2007). Molecular analyses of conserved genes, such as genes encoding 16S rRNA (Lee et al., 1993b), the 16S-23S rRNA intergenic spacer region (Smart et al., 1996), elongation factor EF-Tu (Schneider et al., 1997), preprotein translocation subunit SecY (Lee et al., 2006), transcriptional factor NusA (Shao et al., 2006) and ribosomal proteins RplV and RpsC (Martini et al., 2007), have generated informative data that can be exploited as molecular criteria for the differentiation and classification of phytoplasmas. In particular, Lee and colleagues constructed the first comprehensive phytoplasma classification scheme (Lee et al., 1993b) 
based on restriction fragment length polymorphism (RFLP) analysis of polymerase chain reaction (PCR)-amplified $16 \mathrm{~S}$ rRNA genes, providing a reliable means for the differentiation of a broad array of phytoplasmas. Through periodic updates and revisions (Gundersen et al., 1994; Lee et al., 1998, 2000, 2004a, b), this 16S rRNA gene PCR-RFLP-based classification scheme has become the most widely accepted system for distinguishing and classifying phytoplasma strains.

In the last few years, diverse new phytoplasmas have been discovered at an increasingly rapid pace in numerous emerging diseases worldwide, raising expectations that the number of $16 \mathrm{~S}$ rRNA gene RFLP groups (16Sr groups) and subgroups could rise considerably, inevitably expanding the existing classification scheme. However, attempts to update the classification scheme using conventional RFLP analysis have been hindered by the lack of a complete or near-complete collection of phytoplasma strains as sources of DNA, emphasizing the need for a method to circumvent this obstacle. Recently, we exploited a computer simulated RFLP analysis method for high throughput identification and classification of diverse phytoplasmas (Wei et al., 2007). New phytoplasma groups and subgroups were recognized, significantly expanding the phytoplasma classification consistent with phylogenetic analyses (Wei et al., 2007; Cai et al., 2008). Here we report the development of a computer program that can automatically perform pairwise comparisons of virtual RFLP patterns and determine the coefficients of pattern similarities, obviating the timeconsuming need for visual pattern comparison and manual similarity coefficient calculation. This program streamlines virtual RFLP pattern analysis and has proved to be valuable in unveiling new and distinct phytoplasma group and subgroup lineages.

\section{Program description and usage}

The RFLP pattern comparison and similarity coefficient calculation program was written in Perl (practical extraction and report language) and runs on standard Unix and Linux systems as well as Microsoft Windows. Execution of this program requires no additional system configurations on computers already running Perl.

The program takes in multiple nucleotide sequences in FASTA format (Pearson \& Lipman, 1988), scans through the sequences for the recognition sites of a user-definable list of restriction enzymes, records the length of each restriction fragment and performs pairwise comparisons of the recorded fragment lengths resulting from virtual digestions by each enzyme. The program can be used for virtual RFLP analysis of any gene or DNA region of interest from any organism. In the present study, the input files contained phytoplasma $16 \mathrm{~S}$ rRNA gene F2nR2 regions and the default enzyme list included 17 restriction enzymes [AluI, BamHI, BfaI, BstUI (ThaI), DraI, EcoRI, HaeIII, HhaI, HinfI, HpaI, HpaII, KpnI, Sau3AI (MboI), MseI, RsaI, SspI and TaqI] useful for the differentiation of phytoplasma strains (Lee et al., 1998; Wei et al., 2007). Based on summarized numbers of similar and dissimilar fragments, the program calculates a similarity coefficient $(F)$ for each pair of phytoplasma strains according to the formula described previously (Nei \& Li, 1979): $F=2 N_{x y} /\left(N_{x}+N_{y}\right)$, in which $x$ and $y$ are the two given strains under investigation, $N_{x}$ and $N_{y}$ are the total number of DNA fragments resulting from digestions by 17 enzymes in strains $x$ and $y$, respectively, and $N_{x y}$ is the number of fragments shared by the two strains.

The program is executed interactively from the command line. At the command prompt, after typing in the command perl RFLP_pattern_comparison.pl and pressing the 'Enter' key, users will be further prompted to: (i) enter the input file name (an input file should contain multiple sequences compiled in FASTA format, see the Supplementary material in IJSEM Online for a sample input file), (ii) define the maximum length $(0,1,2,3,4,5$ or 6 nucleotides) by which two DNA fragments can differ yet still be considered as representing the same size during pattern comparison, and (iii) choose one of three output document formats, namely HTML (.html), tab-delimited text (.txt) or Microsoft Excel (.xls). Users who are familiar with Perl command line syntax can enter all program parameters at once at the initial command prompt, for example:

\section{perl RFLP_pattern_comparison.pl my_input.fas $5 \mathrm{html}$}

Execution of the program generates three output files. Snapshots of the three output files are shown in Fig. 1. The first output file (pattern_comparison_result) presents the sum result of total $\left(N_{x}\right.$ and $\left.N_{y}\right)$ and similar $\left(N_{x y}\right)$ fragments (bands) resulting from in silico digestions by all restriction enzymes selected in the enzyme list (Fig. 1a). The second output file (pattern_comparison_detail) documents the details, enzyme-by-enzyme, of the results from RFLP pattern comparisons of each strain pair (Fig. 1b). The third output file (similarity_coefficient_display) displays a matrix of similarity coefficients determined for all strain pairs (Fig. 1c). In order to mimic actual gel electrophoresis-based RFLP analysis, in which DNA fragments smaller than 50 bp cannot be visualized well or accounted for, the program sets $50 \mathrm{bp}$ as the cut-off value; only fragments that are equal to or larger than $50 \mathrm{bp}$ are used in pattern comparison and similarity coefficient calculation.

\section{Criterion for new 16Sr phytoplasma subgroup delineation}

In the $16 \mathrm{~S}$ rRNA gene-based phytoplasma classification system, phytoplasmas are classified into groups based on similarity coefficients of 16S rRNA gene RFLP patterns (Lee et al., 1998, 2000; Wei et al., 2007). Within a given 16Sr group, phytoplasmas are further differentiated into subgroups. Prior to the present work, no threshold similarity coefficient had been established for recognition of new 16Sr subgroups. In previously published work, it 
(a) Virtual RFLP Pattern Comparison Results

\begin{tabular}{|l||c||c||c|c||}
\hline \multicolumn{1}{|c|}{ Strain Pair (x::y) } & $\mathbf{s}_{\mathbf{x}}$ & $\mathbf{x}_{\mathbf{y}}$ & $\mathbf{x}_{\mathbf{x y}}$ & $\mathbf{F}$ \\
\hline \hline M30790(16SII-B)::AY389828(16SrI-A) & 52 & 50 & 47 & 0.92 \\
\hline \hline AF222065(16SrI-C)::AY389828(16SrI-A) & 51 & 50 & 46 & 0.91 \\
\hline \hline AF222065(16SII-C)::M30790(16SrI-B) & 51 & 52 & 48 & 0.93 \\
\hline \hline AY265206(16SrI-D)::AY389828(16SII-A) & 51 & 50 & 46 & 0.91 \\
\hline \hline AY265206(16SrI-D)::M30790(16SrI-B) & 51 & 52 & 50 & 0.97 \\
\hline \hline AY265206(16SrI-D)::AF222065(16SrI-C) & 51 & 51 & 46 & 0.90 \\
\hline \hline AY265213(16SrI-E)::AY389828(16SrI-A) & 51 & 50 & 46 & 0.91 \\
\hline \hline AY265213(16SrI-E)::M30790(16SrI-B) & 51 & 52 & 44 & 0.85 \\
\hline \hline AY265213(16SrI-E)::AF222065(16SrI-C) & 51 & 51 & 47 & 0.92 \\
\hline \hline AY265213(16SrI-E)::AY265206(16SrI-D) & 51 & 51 & 46 & 0.90 \\
\hline \hline AY265211(16SrI-F)::AY389828(16SrI-A) & 48 & 50 & 42 & 0.86 \\
\hline \hline AY265211(16SrI-F)::M30790(16SrI-B) & 48 & 52 & 40 & 0.80 \\
\hline \hline AY265211(16SrI-F)::AF222065(16SII-C) & 48 & 51 & 43 & 0.87 \\
\hline \hline AY265211(16SII-F)::AY265206(16SrI-D) & 48 & 51 & 42 & 0.85 \\
\hline \hline AY265211(16SrI-F)::AY265213(16SrI-E) & 48 & 51 & 43 & 0.87 \\
\hline
\end{tabular}

(b) Virtual RFLP Pattern Comparison Details x: M30790(16SrI-B) x: AF222065(16SrI-C) y: AY389828(16SrI-A) v: AY389828(16SrI-A)

\begin{tabular}{|c|c|c|c|c|c|c|c|}
\hline Enzyme & $x_{x}$ & $x_{y}$ & $N_{x y}$ & Enzyme & $y_{x}$ & $x_{y}$ & $\mathrm{~N}_{\mathrm{xy}}$ \\
\hline AluI(AGCT) & 6 & 6 & 6 & AluI(AGCT) & 6 & 6 & 6 \\
\hline BamHI(GGATCC) & 1 & 1 & $I$ & BamHI(GGATCC) & 1 & 1 & 1 \\
\hline BfaI(CTAG) & 4 & 3 & 2 & $\mathrm{Bfal}(\mathrm{CTAG})$ & 4 & 3 & 2 \\
\hline DraI(TTTAAA) & 2 & 2 & 2 & DraI(TTTAAA) & 2 & 2 & 2 \\
\hline EcoRI(GAATTC) & 2 & 2 & 2 & EcoRI(GAATTC) & 2 & 2 & 2 \\
\hline HaeIII(GGCC) & 2 & 2 & 2 & HaeIII(GGCC) & 2 & 2 & 1 \\
\hline HhaI(GCGC) & 3 & 2 & 1 & HhaI(GCGC) & 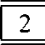 & 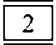 & 2 \\
\hline $\operatorname{HinfI}($ GANTC) & 4 & 4 & 4 & HinfI(GANTC) & 4 & 4 & 4 \\
\hline HpaI(GTTAAC) & 2 & 2 & 2 & HpaI(GTTAAC) & 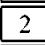 & 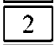 & 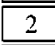 \\
\hline HpaII(CCGG) & 4 & 4 & 4 & HpaII(CCGG) & 4 & 4 & 4 \\
\hline KpnI(GGTACC) & 3 & 3 & 3 & KpnI(GGTACC) & 3 & 3 & 3 \\
\hline MseI(TTAA) & 5 & 5 & 4 & MseI(TTAA) & 5 & 5 & 3 \\
\hline RsaI(GTAC) & 5 & 5 & 5 & RsaI(GTAC) & 5 & 5 & 5 \\
\hline Sau3AI(GATC) & 2 & 2 & 2 & San3AI(GATC) & 2 & 2 & 2 \\
\hline SspI(AATATT) & 1 & 1 & 1 & SspI(AATATT) & 1 & 1 & 1 \\
\hline TaqI(TCGA) & 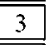 & 3 & $\begin{array}{c}3 \\
\end{array}$ & TaqI(TCGA) & 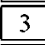 & 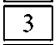 & 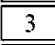 \\
\hline Thal(CGCG) & 3 & 3 & 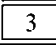 & ThaI(CGCG) & 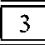 & 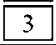 & $\begin{array}{c}3 \\
\end{array}$ \\
\hline
\end{tabular}

(c) Similarity Coefficients Derived from Analysis of Virtual RFLP Patterns

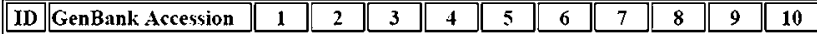
\begin{tabular}{||l|l|l|l|l|}
\hline \hline 1 & AY3389828 (16SII-A) & 1.00 \\
\hline
\end{tabular}

\begin{tabular}{|l|l|l|l|}
\hline \hline 2 & MY30790 (16SrI-B) & 0.92 & 1.00 \\
\hline
\end{tabular}

\begin{tabular}{|l|l|l|l|l|}
\hline \hline 3 & AF222065 (16SII-C) & 0.91 & 0.93 & 1.00 \\
\hline
\end{tabular}

\begin{tabular}{|l|l|l|l|l|l|}
\hline \hline 4 & AY265206 (16Sil-D) & 0.91 & 0.97 & 0.90 & 1.00 \\
\hline \hline
\end{tabular}

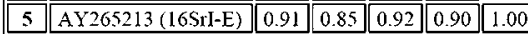

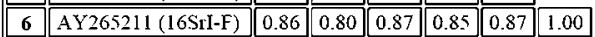

\begin{tabular}{|l||l||l|l||l||l||l|l||l|}
\hline 7 & U96616 (16SrI-K) & 0.86 & 0.69 & 0.85 & 0.61 & 0.86 & 0.86 & 1.00 \\
\hline
\end{tabular}

\begin{tabular}{|l|l|l|l|l|l|l|l|l|l|l|}
\hline \hline $\mathbf{8}$ & AF268405 (16SII-0) & 0.86 & 0.79 & $\mathbf{0 . 8 0}$ & 0.85 & 0.80 & 0.74 & 0.76 & 1.00 \\
\hline
\end{tabular}

\begin{tabular}{|l|l|l|l|l|l|l|l|l|l|l|}
\hline \hline 9 & AF503568 (16SII-P) & 0.92 & 0.94 & 0.93 & 0.91 & 0.93 & 0.94 & 0.92 & 0.80 & 1.00 \\
\hline
\end{tabular}

\begin{tabular}{|l|l|l|l|l|l|l|l|l|l|l||l|l|}
\hline \hline 10 & AY034089 (16SII-Q) & 0.84 & 0.92 & 0.89 & 0.89 & 0.85 & 0.86 & 0.78 & 0.80 & 0.86 & 1.00 \\
\hline
\end{tabular}

Fig. 1. Snapshots of output files from the execution of the RFLP pattern comparison and similarity coefficient calculation program.

has generally been accepted that even one restriction site difference (within the 16S rRNA gene F2nR2 region) between a phytoplasma strain under study and each of the previously established subgroups would qualify the strain to be recognized as the representative of a new subgroup (Lee et al., 1998). With this subgroup designation practice, around 50 16Sr subgroups have so far been described (Lee et al., 2000). Using the program developed in the present study, we performed pairwise comparison and similarity coefficient calculation on virtual 16S rRNA gene RFLP patterns from representative strains of 29 well-established $16 \mathrm{Sr}$ subgroups, each of which represented a distinct phytoplasma lineage possessing unique ecological/biological properties. The results revealed that similarity coefficients between representative strains of any two subgroups within a given $16 \mathrm{Sr}$ group were equal to or lower than 0.97 (Table 1). In an in-depth survey, we used this pattern-comparison and similarity coefficient calculation program on all previously classified phytoplasmas for which $16 \mathrm{~S}$ rRNA gene sequences were available for study. The results showed that some members of certain subgroups exhibited RFLP patterns that were non-identical (giving a similarity coefficient $F=0.99$ or 0.98 ) to those of the designated representative members in the corresponding subgroups. These minor pattern types are denoted with one or two asterisks $\left({ }^{\star}\right.$ or ${ }^{\star *}$ ) following their corresponding subgroup letters, for example $16 \mathrm{SrI}-\mathrm{A}^{*}(F=0.99)$ and 16 SrI- $A^{\star \star}(F=0.98)$. To acknowledge the existing classification status, we propose that the threshold similarity coefficient for new subgroup delineation should be set at 0.97. Thus, a new subgroup is recognized if a phytoplasma strain's virtual 16S rRNA gene RFLP pattern has a 0.97 or lower similarity coefficient with those of all existing representative strains of the given group. Since similarity coefficient values are influenced by both the number and the particular set of restriction enzymes selected for RFLP analysis, the suggestion of 0.97 as the threshold similarity coefficient for new subgroup delineation is strictly based on the use of a specific set of 17 restriction enzymes originally established for the classification of phytoplasmas using actual gel electrophoresis-based RFLP analysis (Lee et al., 1998). The same enzyme list was adopted as the default enzyme list of the similarity coefficient calculation program developed in the present study.

It is well known that many phytoplasmas have two rRNA operons, rrnA and $r r n B$ (Schneider \& Seemüller, 1994; Lauer \& Seemüller, 2000; Padovan et al., 2000; Davis \& Dally, 2001; Oshima et al., 2004; Bai et al., 2006). While the two $r r n$ operons may be identical in some phytoplasma strains, apparent interoperon sequence heterogeneity exists in other strains (Lee et al., 1993b; Firrao et al., 1996; Liefting et al., 1996; Davis \& Sinclair, 1998; Jomantiene et al., 2002). Sequence variations between heterogeneous $\mathrm{rrn}$ operons could affect the restriction sites in the $16 \mathrm{~S}$ rRNA gene F2nR2 region, and as a result, a phytoplasma may exhibit two different virtual 16Sr RFLP patterns. To avoid erroneous assignment of the same phytoplasma into two different 16S rRNA subgroups, we propose a three-letter subgroup designation for those strains from which inter$r r n$ operon sequence heterogeneity has been detected. For example, Paulownia witches'-broom (PaWB) phytoplasma, 
Table 1. Similarity coefficients derived from analysis of virtual RFLP patterns of $16 \mathrm{~S}$ rRNA genes from representative strains of 29 previously established $16 \mathrm{Sr}$ subgroups RFLP pattern similarity coefficients between pairs of subgroup representatives within a given 16Sr group are shaded. They are equal to or lower than $97 \%$.

\begin{tabular}{|c|c|c|c|c|c|c|c|c|c|c|c|c|c|c|c|c|c|c|c|c|c|c|c|c|c|c|c|c|c|c|}
\hline $\begin{array}{l}\text { Serial } \\
\text { no. }\end{array}$ & $\begin{array}{l}\text { Subgroup representative } \\
\text { (GenBank accession no.) }\end{array}$ & 1 & 2 & 3 & 4 & 5 & 6 & 7 & 8 & 9 & 10 & 11 & 12 & 13 & 14 & 15 & 16 & 17 & 18 & 19 & 20 & 21 & 22 & 23 & 24 & 25 & 26 & 27 & 28 & 29 \\
\hline 1 & 16SrI-A (AY389828) & 1.00 & & & & & & & & & & & & & & & & & & & & & & & & & & & & \\
\hline 2 & 16SrI-B (M30790) & 0.92 & 1.00 & & & & & & & & & & & & & & & & & & & & & & & & & & & \\
\hline 3 & 16SrI-C (AF222065) & 0.91 & 0.93 & 1.00 & & & & & & & & & & & & & & & & & & & & & & & & & & \\
\hline 4 & 16SrI-D (AY265206) & 0.91 & 0.97 & 0.90 & 1.00 & & & & & & & & & & & & & & & & & & & & & & & & & \\
\hline 5 & 16Srl-E (AY265213) & 0.91 & 0.85 & 0.92 & 0.90 & 1.00 & & & & & & & & & & & & & & & & & & & & & & & & \\
\hline 6 & 16SrI-F (AY265211) & 0.86 & 0.80 & 0.87 & 0.85 & 0.87 & 1.00 & & & & & & & & & & & & & & & & & & & & & & & \\
\hline 7 & 16SrI-K (U96616) & 0.86 & 0.69 & 0.85 & 0.61 & 0.86 & 0.86 & 1.00 & & & & & & & & & & & & & & & & & & & & & & \\
\hline 8 & 16SrI-O (AF268405) & 0.86 & 0.79 & 0.80 & 0.85 & 0.80 & 0.74 & 0.76 & 1.00 & & & & & & & & & & & & & & & & & & & & & \\
\hline 9 & 16SrI-P (AF503568) & 0.92 & 0.94 & 0.93 & 0.91 & 0.93 & 0.94 & 0.92 & 0.80 & 1.00 & & & & & & & & & & & & & & & & & & & & \\
\hline 10 & 16SrI-Q (AY034089) & 0.84 & 0.92 & 0.89 & 0.89 & 0.85 & 0.86 & 0.78 & 0.80 & 0.86 & 1.00 & & & & & & & & & & & & & & & & & & & \\
\hline 11 & 16SrII-A (L33765) & 0.47 & 0.48 & 0.46 & 0.48 & 0.35 & 0.38 & 0.29 & 0.34 & 0.49 & 0.45 & 1.00 & & & & & & & & & & & & & & & & & & \\
\hline 12 & 16SrII-B (U15442) & 0.46 & 0.49 & 0.45 & 0.47 & 0.45 & 0.48 & 0.32 & 0.39 & 0.48 & 0.42 & 0.88 & 1.00 & & & & & & & & & & & & & & & & & \\
\hline 13 & 16SrII-C (X83432) & 0.50 & 0.52 & 0.49 & 0.51 & 0.49 & 0.55 & 0.36 & 0.43 & 0.51 & 0.46 & 0.94 & 0.94 & 1.00 & & & & & & & & & & & & & & & & \\
\hline 14 & 16SrII-D (Y10097) & 0.49 & 0.52 & 0.49 & 0.50 & 0.49 & 0.52 & 0.35 & 0.42 & 0.51 & 0.45 & 0.95 & 0.91 & 0.97 & 1.00 & & & & & & & & & & & & & & & \\
\hline 15 & 16SrV-A (AF 122910) & 0.52 & 0.47 & 0.49 & 0.45 & 0.29 & 0.34 & 0.33 & 0.39 & 0.48 & 0.44 & 0.48 & 0.47 & 0.52 & 0.51 & 1.00 & & & & & & & & & & & & & & \\
\hline 16 & 16SrV-B (AB052876) & 0.50 & 0.45 & 0.47 & 0.43 & 0.43 & 0.38 & 0.31 & 0.43 & 0.46 & 0.42 & 0.53 & 0.52 & 0.56 & 0.55 & 0.93 & 1.00 & & & & & & & & & & & & & \\
\hline 17 & 16SrV-C (AY197642) & 0.49 & 0.44 & 0.47 & 0.45 & 0.41 & 0.38 & 0.31 & 0.42 & 0.45 & 0.41 & 0.48 & 0.47 & 0.51 & 0.51 & 0.97 & 0.90 & 1.00 & & & & & & & & & & & & \\
\hline 18 & 16SrVI-A (AY390261) & 0.49 & 0.50 & 0.46 & 0.48 & 0.34 & 0.39 & 0.30 & 0.33 & 0.45 & 0.40 & 0.52 & 0.51 & 0.55 & 0.54 & 0.89 & 0.89 & 0.86 & 1.00 & & & & & & & & & & & \\
\hline 19 & 16SrVI-B (AF190225) & 0.38 & 0.42 & 0.38 & 0.34 & 0.32 & 0.37 & 0.30 & 0.31 & 0.36 & 0.32 & 0.52 & 0.34 & 0.38 & 0.38 & 0.82 & 0.82 & 0.79 & 0.93 & 1.00 & & & & & & & & & & \\
\hline 20 & 16SrVI-C (AF228053) & 0.56 & 0.51 & 0.53 & 0.49 & 0.45 & 0.42 & 0.27 & 0.46 & 0.52 & 0.47 & 0.54 & 0.53 & 0.57 & 0.57 & 0.90 & 0.90 & 0.87 & 0.94 & 0.87 & 1.00 & & & & & & & & & \\
\hline 21 & 16SrX-A (AJ542541) & 0.52 & 0.43 & 0.52 & 0.47 & 0.49 & 0.53 & 0.53 & 0.47 & 0.48 & 0.46 & 0.34 & 0.39 & 0.43 & 0.45 & 0.35 & 0.35 & 0.39 & 0.38 & 0.31 & 0.43 & 1.00 & & & & & & & & \\
\hline 22 & 16SrX-C (AJ542543) & 0.53 & 0.43 & 0.52 & 0.48 & 0.52 & 0.56 & 0.55 & 0.49 & 0.48 & 0.46 & 0.35 & 0.40 & 0.44 & 0.45 & 0.35 & 0.35 & 0.39 & 0.38 & 0.31 & 0.44 & 0.97 & 1.00 & & & & & & & \\
\hline 23 & 16SrX-D (X92869) & 0.57 & 0.46 & 0.59 & 0.55 & 0.53 & 0.56 & 0.56 & 0.50 & 0.55 & 0.53 & 0.30 & 0.36 & 0.40 & 0.40 & 0.32 & 0.32 & 0.34 & 0.39 & 0.35 & 0.42 & 0.81 & 0.84 & 1.00 & & & & & & \\
\hline 24 & 16SrX-F (AJ542544) & 0.54 & 0.44 & 0.53 & 0.49 & 0.53 & 0.55 & 0.56 & 0.51 & 0.49 & 0.47 & 0.34 & 0.39 & 0.43 & 0.42 & 0.37 & 0.37 & 0.40 & 0.40 & 0.33 & 0.42 & 0.88 & 0.91 & 0.78 & 1.00 & & & & & \\
\hline 25 & 16SrXII-A (AJ964960) & 0.85 & 0.80 & 0.88 & 0.85 & 0.87 & 0.81 & 0.80 & 0.74 & 0.87 & 0.82 & 0.42 & 0.44 & 0.48 & 0.48 & 0.38 & 0.42 & 0.42 & 0.35 & 0.33 & 0.46 & 0.48 & 0.51 & 0.51 & 0.54 & 1.00 & & & & \\
\hline 26 & 16SrXII-B (L76865) & 0.84 & 0.73 & 0.82 & 0.82 & 0.80 & 0.80 & 0.80 & 0.73 & 0.86 & 0.73 & 0.42 & 0.45 & 0.49 & 0.50 & 0.41 & 0.45 & 0.46 & 0.35 & 0.31 & 0.48 & 0.53 & 0.56 & 0.50 & 0.55 & 0.86 & 1.00 & & & \\
\hline 27 & 16SrXII-C (AJ243045) & 0.88 & 0.76 & 0.85 & 0.83 & 0.83 & 0.84 & 0.84 & 0.75 & 0.90 & 0.76 & 0.43 & 0.46 & 0.50 & 0.51 & 0.44 & 0.48 & 0.47 & 0.38 & 0.34 & 0.52 & 0.54 & 0.57 & 0.51 & 0.56 & 0.89 & 0.96 & 1.00 & & \\
\hline 28 & 16SrXII-D (AB010425) & 0.68 & 0.76 & 0.75 & 0.73 & 0.69 & 0.78 & 0.68 & 0.63 & 0.76 & 0.74 & 0.41 & 0.40 & 0.44 & 0.43 & 0.44 & 0.42 & 0.41 & 0.36 & 0.30 & 0.47 & 0.40 & 0.40 & 0.47 & 0.43 & 0.76 & 0.73 & 0.76 & 1.00 & \\
\hline 29 & 16SrXII-E (DQ086423) & 0.83 & 0.90 & 0.88 & 0.87 & 0.83 & 0.77 & 0.76 & 0.78 & 0.83 & 0.85 & 0.45 & 0.44 & 0.48 & 0.48 & 0.46 & 0.44 & 0.44 & 0.39 & 0.31 & 0.50 & 0.46 & 0.47 & 0.53 & 0.48 & 0.89 & 0.80 & 0.83 & 0.83 & 1.00 \\
\hline
\end{tabular}


a member of the previously delineated subgroup 16SrI-D, possesses two sequence-heterogeneous rRNA operons displaying two different 16Sr RFLP patterns, 16SrI-B and 16 SrI-D, therefore the subgroup status of PaWB is redesignated $16 \mathrm{SrI}-(\mathrm{B} / \mathrm{D}) \mathrm{D}$. In this subgroup designation, the first and second letters (in parentheses) denote the RFLP pattern types of $r r n A$ and $r r n B$, respectively, and the third letter designates the 16Sr subgroup.

\section{Recognition of new subgroups in the clover proliferation phytoplasma group (16SrVI)}

Clover proliferation disease of alsike clover was first described in the early 1960s as a yellows type virus disease. It was not until the mid-1970s that the aetiological agent of the disease was determined to be a phytoplasma (Hiruki \& Wang, 2004). Since then, many emerging and previously unknown diseases have been found to be associated with infection by various phytoplasma strains of the clover proliferation group (16SrVI). In the present study, a sequence similarity analysis performed by using the basic local alignment search tool (BLAST, Altschul et al., 1990) on more than 900 available phytoplasma 16S rRNA gene sequence entries in GenBank revealed that 30 entries shared more than $97.5 \%$ sequence similarity with each other and with that of 'Candidatus Phytoplasma trifolii' reference strain CP. A subsequent minimal evolution phylogenetic analysis using a close neighbour interchange algorithm (MEGA4, Tamura et al., 2007) resulted in a phytoplasma $16 \mathrm{~S}$ rRNA gene tree in which the 30 entries formed a distinct subclade (Fig. 2). These results indicated that these 30 strains are closely related to ' $\mathrm{C}$. Phytoplasma trifolii', the representative of group 16SrVI. However, a literature review revealed that only 13 out of the 30 strains had been formally classified as members of group $16 \mathrm{Sr}-\mathrm{VI}$ and their subgroup status determined. Of the $3016 \mathrm{~S}$ rRNA gene sequence entries, one (GenBank accession no. AF268895) did not encompass the entire F2nR2 region and was excluded from further study. With the new program, in silico restriction digestions and pairwise virtual RFLP pattern comparisons were performed on the remaining 29 potential $16 \mathrm{SrVI}$ entries and the reference strains of each previously delineated phytoplasma $16 \mathrm{Sr}$ group as well as the reference strains of all 'Candidatus Phytoplasma' organisms. As evidenced by the resulting coefficients of pattern similarity (see Supplementary Table S1), all 29 entries were confirmed as members of group 16SrVI. The program operation concluded that virtual RFLP analysis of the 29 16SrVI entries yielded 11 pattern types. The 11 distinct RFLP patterns were plotted as virtual gel images (Fig. 3) using the program pDRAw32 (AcaClone Software, http://www.acaclone.com) as described previously (Wei et al., 2007). Of the 11 pattern types, three represented the documented patterns of the three previously delineated 16SrVI subgroups. These included clover proliferation phytoplasma CP subgroup (16SrVI-A), Oregon 'Fragaria multicipita' phytoplasma MC subgroup (16SrVI-B) and Illinois elm yellows phytoplasma subgroup (16SrVI-C). The discovery of a total of eight new RFLP pattern types clearly points to the presence of distinct variants and new subgroups in the 16SrVI phytoplasma group. Four of the eight pattern types shared similarity coefficients of less than 0.97 with each other and with each of the three known subgroups (Table 2). Thus, based on the calculated pattern similarity coefficients, at least four new 16SrVI subgroups can be proposed. These new subgroups are: subgroup $16 \mathrm{SrVI}-\mathrm{D}$, represented by Indian brinjal little leaf (BLL-In) phytoplasma (GenBank accession nos X83431 and EF186820); subgroup 16SrVI-E, represented by Italian Centaurea solstitialis virescence (CSV) phytoplasma (AY270156); subgroup 16SrVI-F, represented by Sudanese periwinkle phyllody (CPS) phytoplasma (EF186819) and subgroup $16 \mathrm{SrVI}-\mathrm{H}$, represented by Indian portulaca little leaf phytoplasma (EF651786) (Fig. 3). In addition, the virtual RFLP pattern type derived from $r r n B$ of the Canadian 'Fragaria multicipita' phytoplasma MC strain (AF190225, previously placed in 16SrVI-B) is also new and significantly distinct from those of representative strains in other subgroups, sharing similarity coefficients of lower than 0.97 with any other subgroups; therefore the new pattern type is designated 16SrVI-G, and the subgroup status of the Canadian 'Fragaria multicipita' phytoplasma MC is redesignated $16 \mathrm{SrVI}-(\mathrm{B} / \mathrm{G}) \mathrm{B}$. Two additional new RFLP pattern types identified in the present study were derived from the 16S rRNA gene of the Washington dry bean phyllody phytoplasma strain DBPh2 (AY496002) and rrnA of Illinois elm yellows phytoplasma, respectively (Fig. 3). As both patterns shared a similarity coefficient of 0.98 with the documented pattern of subgroup 16SrVI-A, these two pattern types are considered as variants of $16 \mathrm{SrVI}-\mathrm{A}$. Since Illinois elm yellows phytoplasma possesses two sequenceheterogeneous rRNA operons exhibiting different 16Sr RFLP patterns, 16SrVI-A ${ }^{\star *}$ and $16 \mathrm{SrVI}-\mathrm{C}$, the subgroup status of Illinois elm yellows phytoplasma is redesignated as $16 \mathrm{SrVI}-$ $\left(A^{* \star} / C\right) C$. The remaining one new RFLP pattern, displayed by both Bangladesh brinjal little leaf phytoplasma (BLL-Bd, AF228052) and Bangladesh periwinkle little leaf phytoplasma (PLL-Bd, AF228053), had a calculated pattern similarity coefficient of 0.97 when compared with the pattern of subgroup $16 \mathrm{SrVI}-\mathrm{D}$, and is therefore considered as a variant of $16 \mathrm{SrVI}-\mathrm{D}$.

Phytoplasmas in the four new 16SrVI subgroups revealed in the present study are associated with emerging diseases in specific hosts and geographical areas (Siddique et al., 2001; Faggioli et al., 2004; Martini et al., 2007). These phytoplasmas represent distinct lineages whose evolutionary history, host range, vectorship and other biological properties have yet to be determined. Recognition of these new subgroups provides molecular markers for quick identification and differentiation of phytoplasmas in the rapidly expanding $16 \mathrm{SrVI}$ group. A closer examination of the virtual RFLP pattern types revealed that subgroup-level differentiation of phytoplasma strains in group $16 \mathrm{SrVI}$ could be achieved by virtual or laboratory digestion of $16 \mathrm{~S}$ rRNA gene F2nR2 fragments by four key restriction enzymes (Fig. 4). 


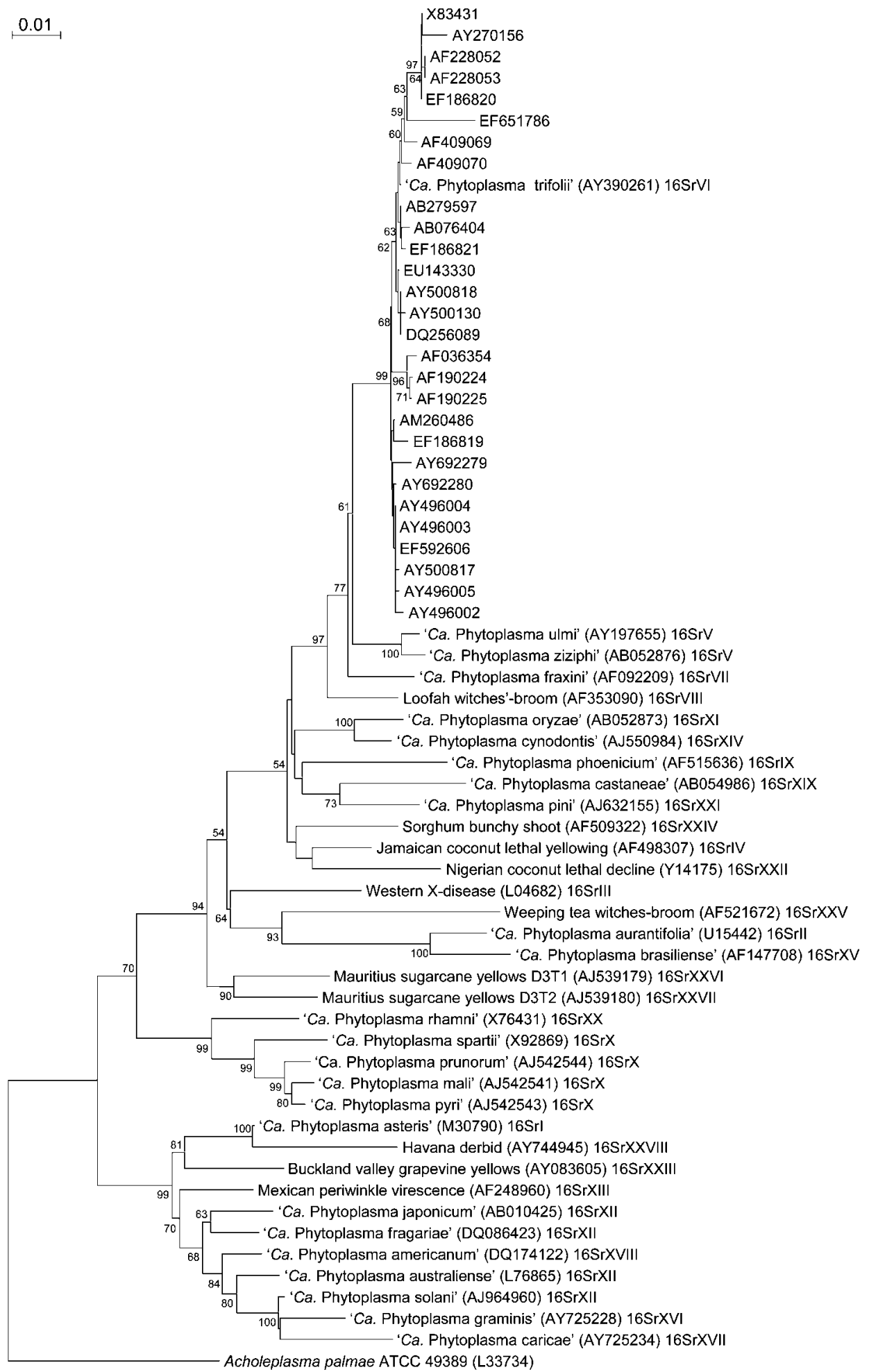

Fig. 2. Phylogenetic tree inferred from analysis of $16 \mathrm{~S}$ rRNA gene sequences. Minimal evolution analysis was conducted using the close neighbour interchange $(\mathrm{CNI})$ algorithm. The initial tree for the $\mathrm{CNI}$ search was obtained by the neighbour-joining method. The reliability of the analysis was subjected to a bootstrap test with 500 replicates. The taxa used in the phylogenetic tree reconstruction included reference strains of each phytoplasma $16 \mathrm{Sr}$ group and reference strains of each 'Candidatus Phytoplasma' species ('Ca. Phytoplasma allocasuarinae' and 'Ca. Phytoplasma lycopersici' were not included because the available 16S rRNA gene sequences did not encompass the entire F2nR2 region). Acholeplasma palmae served as an outgroup during the phylogenetic tree reconstruction. Bar, 0.01 nucleotide substitutions per site. 
Table 2. Similarity coefficients derived from analysis of virtual RFLP patterns of $16 \mathrm{~S}$ rRNA genes from phytoplasma strains in the clover proliferation group (16SrVI)

New subgroups (RFLP pattern types) delineated in the present study are shaded. For each strain of a new subgroup, the similarity coefficients are equal to or lower than 0.97 with all strains in previously delineated subgroups. Asterisks indicate variants of the designated subgroup.

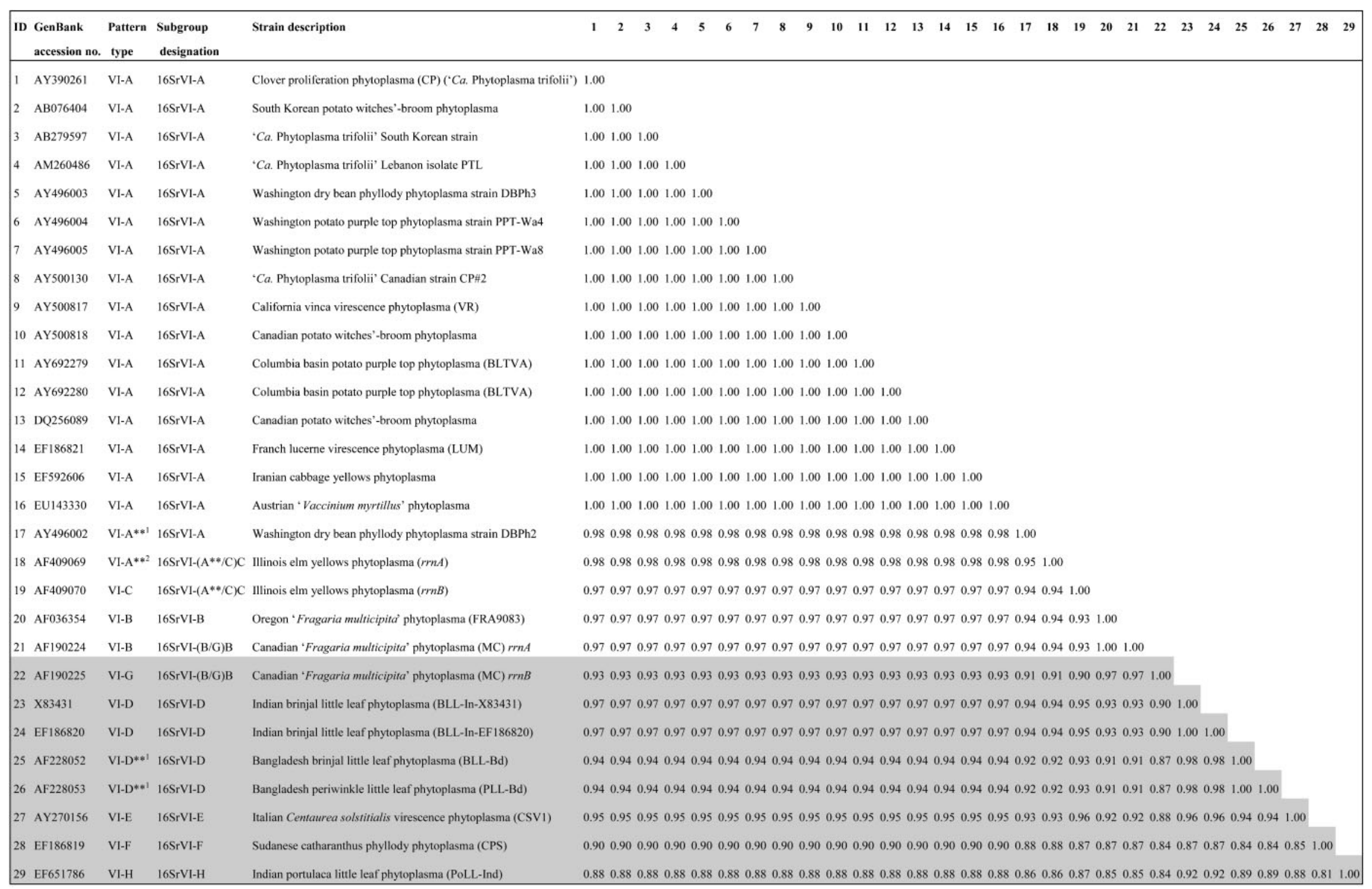




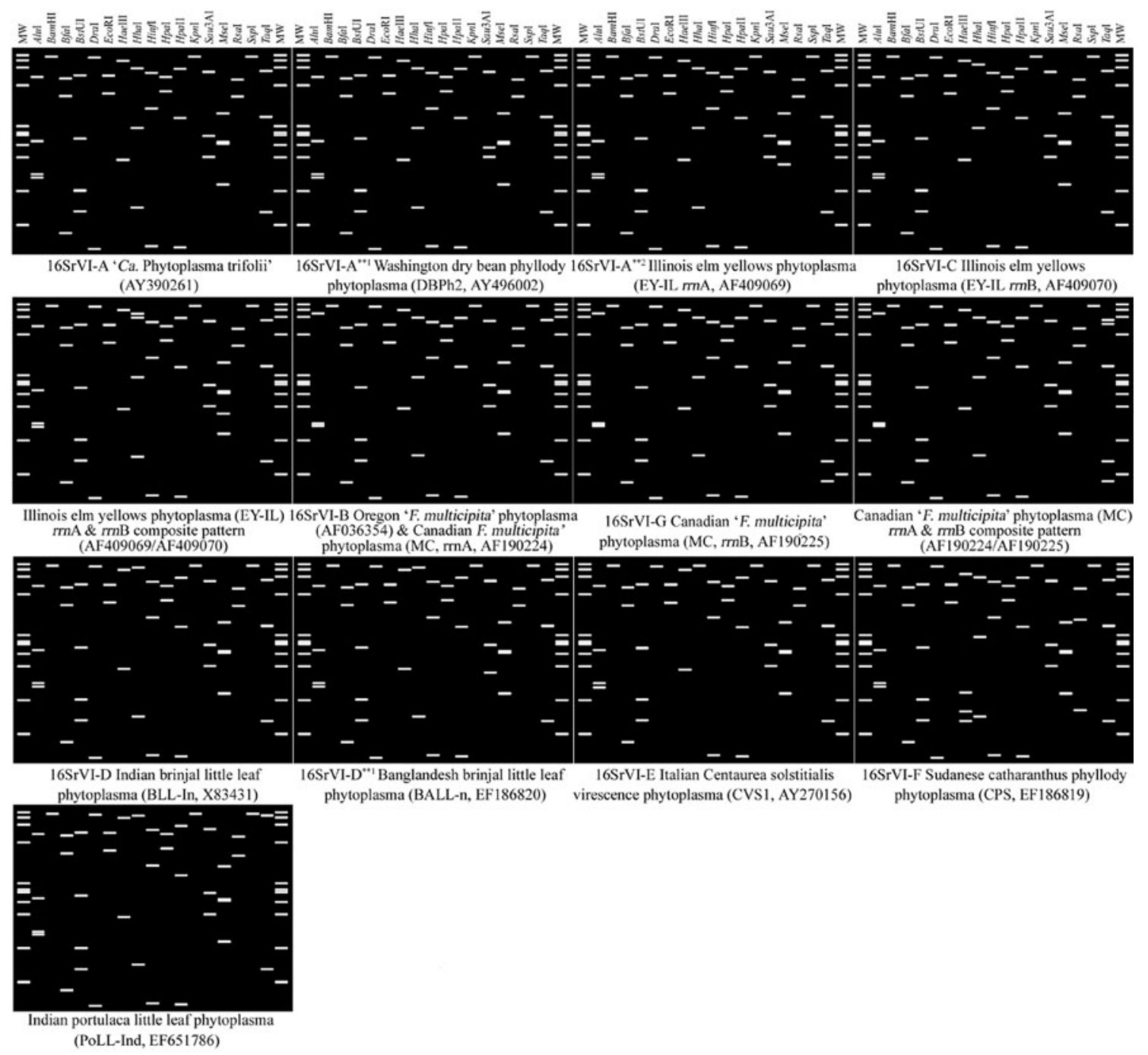

Fig. 3. Distinct virtual RFLP patterns derived from in silico digestions of $16 \mathrm{~S}$ rRNA gene F2nR2 fragments from strains of new and previously delineated $16 \mathrm{SrVI}$ subgroups. Recognition sites for the following 17 restriction enzymes were used in the simulated digestions: Alul, BamHI, Bfal, BstUl (Thal), Dral, EcoRl, Haell, Hhal, Hinfl, Hpal, Hpall, Kpnl, Sau3Al (Mbol), Msel, Rsal, Sspl, and Taql. MW, $\varphi$ X174DNA-Haell digestion.

In conclusion, by eliminating time-consuming pairwise visual comparisons of multiple RFLP pattern types and tedious calculations of similarity coefficients, the computer program developed in the present study streamlines virtual RFLP pattern analysis, facilitating the discovery of new phytoplasma lineages. The use of this program has led to the establishment of a criterion for phytoplasma $16 \mathrm{Sr}$ subgroup classification and has unveiled previously unrecognized/ unclassified phytoplasma subgroup lineages and distinct variants in the clover proliferation phytoplasma group, further highlighting the genetic diversity and biological complexity of phytoplasmas in this group. The findings from this study expand the classification of phytoplasmas and demonstrate the value of streamlined virtual RFLP analysis in the identification and differentiation of closely related phytoplasmas. The Perl program developed in the current study can also be exploited for virtual RFLP analysis of other phytoplasmal genes and genes of other organisms. A webbased interface is currently being developed to further implement this program, paving a way for transforming phytoplasma classification from actual gel-based individual laboratory procedures to a virtual gel-based real-time World Wide Web operation. The virtual gel analysis and phytoplasma classification web server will be hosted by the Molecular Plant Pathology Laboratory at http://www.ba. ars.usda.gov/data/mppl/virtualgel.html. 


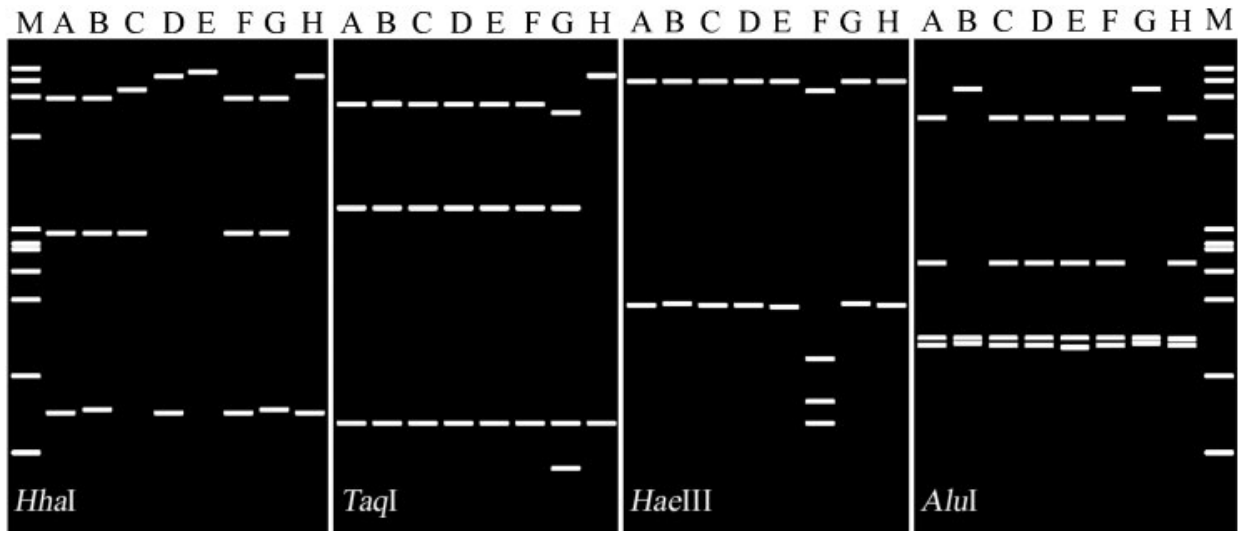

Fig. 4. Key restriction enzymes that distinguish eight $16 \mathrm{SrVI}$ subgroup pattern types. Subgroup patterns $16 \mathrm{SrVI}-\mathrm{C}$ and $16 \mathrm{SrVI}-\mathrm{E}$ can be separated from the other pattern types by Hhal digestion alone. The remaining six pattern types can be distinguished by digestion using additional enzymes as follows: distinction between 16SrVI-D and 16SrVI-H and separation of 16SrVI-G from 16SrVI-A, 16SrVI-B, and 16SrVI-F can be achieved by Taql digestion; separation of 16SrVI-F from 16SrVI-A and $16 \mathrm{SrVI}-\mathrm{B}$ can be accomplished by Haell digestion; and the final differentiation between 16SrVI-A and 16SrVI-B can be made by Alul digestion. The letters $\mathrm{A}-\mathrm{H}$ represent the different $16 \mathrm{SrVI}$ subgroups; $\mathrm{M}, \varphi \mathrm{X} 174 \mathrm{DNA}-$ Haell digestion as a marker.

\section{References}

Altschul, S. F., Gish, W., Miller, W., Myers, E. W. \& Lipman, D. J. (1990). Basic local alignment search tool. J Mol Biol 215, 403-410.

Bai, X., Zhang, J. H., Ewing, A., Miller, S. A., Radek, A. J., Shevchenko, D. V., Tsukerman, K., Walunas, T., Lapidus, A. \& other authors (2006). Living with genome instability: the adaptation of phytoplasmas to diverse environments of their insect and plant hosts. J Bacteriol 188, 3682-3696.

Cai, H., Wei, W., Davis, R. E., Chen, H. \& Zhao, Y. (2008). Genetic diversity among phytoplasmas infecting Opuntia spp.: virtual RFLP analysis identifies new subgroups in the peanut witches'-broom phytoplasma group. Int J Syst Evol Microbiol 58, 1448-1457.

Chiykowski, L. N. (1962). Clover phyllody virus in Canada and its transmission. Can J Bot 40, 397-404.

Chiykowski, L. N. \& Sinha, R. C. (1989). Differentiation of MLO disease by means of symptomatology and vector transmission. Zentralbl Bakteriol Hyg (Suppl) 20, 280-287.

Davis, R. E. \& Dally, E. L. (2001). Nonfunctional tRNA gene in an unusual example of rRNA interoperon sequence heterogeneity in phytoplasma. Phytopathology 91, S21.

Davis, R. E. \& Sinclair, W. A. (1998). Phytoplasma identity and disease etiology. Phytopathology 88, 1372-1376.

Faggioli, F., Pasquini, G., Lumia, V., Campobasso, G., Widmer, T. L. \& Quimby, P. C., Jr (2004). Molecular identification of a new member of the clover proliferation phytoplasma group (16SrVI) associated with Centaurea solstitialis virescence in Italy. Eur J Plant Pathol 110, 353360.

Firrao, G., Carraro, L., Gobbi, E. \& Locci, R. (1996). Molecular characterization of a phytoplasma causing phyllody in clover and other herbaceous hosts in northern Italy. Eur J Plant Pathol 102, 817-822.

Freitag, J. H. (1964). Interaction and mutual suppression among three strains of aster yellows virus. Virology 24, 401-413.

Granados, R. R. \& Chapman, R. K. (1968). Identification of some new aster yellows virus strains and their transmission by the aster leafhopper Macrosteles fascifrons (Stahl). Phytopathology 58, 16851692.
Gundersen, D. E., Lee, I. M., Rehner, S. A., Davis, R. E. \& Kingsbury, D. T. (1994). Phylogeny of mycoplasmalike organisms (phytoplasmas): a basis for their classification. J Bacteriol 176, 5244-5254.

Hiruki, C. \& Wang, K. R. (2004). Clover proliferation phytoplasma: 'Candidatus Phytoplasma trifolii'. Int J Syst Evol Microbiol 54, 13491353.

Jomantiene, R., Davis, R. E., Valiunas, D. \& Alminaite, A. (2002). New group 16SrIII phytoplasma lineages in Lithuania exhibit rRNA interoperon sequence heterogeneity. Eur J Plant Pathol 108, 507-517. Lauer, U. \& Seemüller, E. (2000). Physical map of the chromosome of the apple proliferation phytoplasma. J Bacteriol 182, 1415-1418.

Lee, I.-M. \& Davis, R. E. (1988). Detection and investigation of genetic relatedness among aster yellows and other mycoplasma-like organisms by using cloned DNA and RNA probes. Mol Plant Microbe Interact 1, 303-310.

Lee, I.-M., Davis, R. E., Chen, T.-A., Chiykowski, L. N., Fletcher, J., Hiruki, C. \& Schaff, D. A. (1992a). A genotype-based system for identification and classification of mycoplasmalike organisms (MLOs) in the aster yellows MLO strain cluster. Phytopathology 82, 977-986.

Lee, I.-M., Gundersen, D. E., Davis, R. E. \& Chiykowske, L. N. (1992b). Identification and analysis of a genomic strain cluster of mycoplasmalike organisms associated with Canadian peach (eastern) $\mathrm{X}$-disease, Western X-disease, and clover yellow edge. J Bacteriol 174, 6694-6698.

Lee, I.-M., Davis, R. E. \& Hsu, H.-T. (1993a). Differentiation of strains in the aster yellows mycoplasmalike organism strain cluster by serological assays with monoclonal antibodies. Plant Dis 77, 815817.

Lee, I.-M., Hammond, R. W., Davis, R. E. \& Gundersen, D. E. (1993b). Universal amplification and analysis of pathogen $16 \mathrm{~S}$ rDNA for classification and identification of mycoplasmalike organisms. Phytopathology 83, 834-842.

Lee, I.-M., Gundersen-Rindal, D. E., Davis, R. E. \& Bartoszyk, I. M. (1998). Revised classification scheme of phytoplasmas based on RFLP analyses of $16 \mathrm{~S}$ rRNA and ribosomal protein gene sequences. Int J Syst Bacteriol 48, 1153-1169. 
Lee, I.-M., Davis, R. E. \& Gundersen-Rindal, D. E. (2000). Phytoplasma: phytopathogenic mollicutes. Annu Rev Microbiol 54, 221-255.

Lee, I.-M., Gundersen-Rindal, D. E., Davis, R. E., Bottner, K. D., Marcone, C. \& Seemüller, E. (2004a). 'Candidatus Phytoplasma asteris', a novel phytoplasma taxon associated with aster yellows and related diseases. Int J Syst Evol Microbiol 54, 1037-1048.

Lee, I.-M., Martini, M., Macone, C. \& Zhu, S. F. (2004b). Classification of phytoplasma strains in the elm yellows group (16SrV) and proposal of 'Candidatus phytoplasma ulmi' for the phytoplasma associated with elm yellows. Int J Syst Evol Microbiol 54, 337-347.

Lee, I.-M., Zhao, Y. \& Bottner, K. D. (2006). SecY gene sequence analysis for finer differentiation of diverse strains in the aster yellows phytoplasma groups. Mol Cell Probes 20, 87-91.

Lee, I.-M., Zhao, Y., Davis, R. E., Wei, W. \& Martini, M. (2007). Prospects of DNA-based systems for differentiation and classification of phytoplasmas. Bull Insectol 60, 239-244.

Liefting, L. W., Andersen, M. T., Beever, R. E., Gardner, R. C. \& Foster, L. S. (1996). Sequence heterogeneity in the two 16S rRNA genes of Phormium yellow leaf phytoplasma. Appl Environ Microbiol 62, 3133-3139.

Lin, C.-P. \& Chen, T.-A. (1985). Monoclonal antibodies against the aster yellows agent. Science 227, 1233-1235.

Martini, M., Lee, I.-M., Bottner, K. D., Zhao, Y., Botti, S., Bertaccini, A., Harrison, N. A., Carraro, L., Marcone, C. \& Osler, R. (2007). Ribosomal protein gene-based phylogeny for finer differentiation and classification of phytoplasmas. Int J Syst Evol Microbiol 57, 2037-2051.

McCoy, R. E., Caudwell, A., Chang, C. J., Chen, T. A., Chiykowski, L. N., Cousin, M. T., Dale, J. L., de Leeuw, G. T. N., Golino, D. A. \& other authors (1989). Plant diseases associated with mycoplasmalike organisms. In The Mycoplasmas, vol 5, pp. 545-560. Edited by R. F. Whitcomb \& J. G. Tully. New York: Academic Press.

Nei, M. \& Li, W.-H. (1979). Mathematical model for studying genetic variation in terms of restriction endonucleases. Proc Natl Acad Sci U S A 76, 5269-5273.

Oshima, K., Kakizawa, S., Nishigawa, H., Jung, H.-Y., Wei, W., Suzuki, S., Arashida, R., Nakata, D., Miyata, S. \& other authors (2004). Reductive evolution suggested from the complete genome sequence of a plant-pathogenic phytoplasma. Nat Genet 36, 27-29.

Padovan, A. C., Firrao, G., Schneider, B. \& Gibb, K. S. (2000). Chromosome mapping of the sweet potato little leaf phytoplasma reveals genome heterogeneity within the phytoplasmas. Microbiology 146, 893-902.

Pearson, W. R. \& Lipman, D. J. (1988). Improved tools for biological sequence comparison. Proc Natl Acad Sci U S A 85, 2444-2448.

Razin, S., Yogev, D. \& Naot, Y. (1998). Molecular biology and pathology of mycoplasmas. Microbiol Mol Biol Rev 62, 1094-1156.

Schneider, B. \& Seemüller, E. (1994). Presence of two sets of ribosomal genes in phytopathogenic mollicutes. Appl Environ Microbiol 60, 3409-3412.

Schneider, B., Gibb, K. S. \& Seemüller, E. (1997). Sequence and RFLP analysis of the elongation factor Tu gene used in differentiation and classification of phytoplasmas. Microbiology 143, 3381-3389.

Shao, J. Y., Jomantiene, R., Dally, E. L., Zhao, Y., Lee, I.-M., Nuss, D. L. \& Davis, R. E. (2006). NusA: comparative properties, phylogeny, and use in detection of group 16Srl phytoplasmas. J Plant Pathol 88, 193201.

Siddique, A., Agrawal, G. K., Alam, N. \& Krishnareddy, M. (2001). Electron microscopy and molecular characterization of phytoplasmas associated with little leaf disease of brinjal (Solanum melongena L.) and periwinkle (Catharanthus roseus) in Bangladesh. J Phytopathol 149, 237-244.

Smart, C. D., Schneider, B., Blomquist, C. L., Guerra, L. J., Harrison, N. A., Ahrens, U., Lorenz, K.-H., Seemüller, E. \& Kirkpatrick, B. C. (1996). Phytoplasma-specific PCR primers based on sequences of 16S-23S rRNA spacer region. Appl Environ Microbiol 62, 2988-2993.

Tamura, K., Dudley, J., Nei, M. \& Kumar, S. (2007). MEGA4: molecular evolutionary genetics analysis (MEGA) software version 4.0. Mol Biol Evol 24, 1596-1599.

Tsai, J. H. (1979). Vector transmission of mycoplasmal agents of plant diseases. In The Mycoplasmas III, Plant and Insect Mycoplasmas, pp. 265-307. Edited by R. F. Whitcomb \& J. G. Tully. New York: Academic Press.

Wei, W., Davis, R. E., Lee, I.-M. \& Zhao, Y. (2007). Computersimulated RFLP analysis of $16 \mathrm{~S}$ rRNA genes: identification of ten new phytoplasma groups. Int J Syst Evol Microbiol 57, 1855-1867.

Weisburg, W. G., Tully, J. G., Rose, D. L., Petzel, J. P., Oyaizu, H., Yang, D., Mandelco, L., Sechrest, J., Lawrence, T. G. \& other authors (1989). A phylogenetic analysis of the mycoplasmas: basis for their classification. J Bacteriol 171, 6455-6467. 